\title{
A Scheme for Jointly Trading off Costs and Risks of Solar Radiation Management and Mitigation Under Long-Tailed Climate Sensitivity Probability Density Distributions
}

\author{
Elnaz $\operatorname{Roshan}^{1}$ (D) Mohammad M. Khabbazan ${ }^{1,2} \cdot$ Hermann Held ${ }^{1}$
}

Received: 23 January 2020 / Accepted: 13 June 2021 / Published online: 10 July 2021

(c) The Author(s) 2021

\begin{abstract}
Side effects of "solar-radiation management" (SRM) might be perceived as an important metric when society decides on implementing SRM as a climate policy option to alleviate anthropogenic global warming. We generalize cost-risk analysis that originally trades off expected welfare loss from climate policy costs and risks from transgressing climate targets to also include risks from applying SRM. In a first step of acknowledging SRM risks, we represent global precipitation mismatch as a prominent side effect of SRM under long-tailed probabilistic knowledge about climate sensitivity. We maximize a social welfare function for the following three scenarios, considering alternative relative weights of risks: temperature-risk-only, precipitation-risk-only, and equally-weighted both-risks. Our analysis shows that in the temperature-risk-only scenario, perfect compliance with the $2{ }^{\circ} \mathrm{C}$-temperature target is attained for all numerically represented climate sensitivities, a unique feature of SRM, but the $2{ }^{\circ} \mathrm{C}$-compatible precipitation corridor is violated. The precipitation-risk-only scenario exhibits an approximate mirror-image of this result. In addition, under the both-risks scenario, almost $90 \%$ and perfect compliance can be achieved for the temperature and precipitation targets, respectively. Moreover, in a mitigation-only analysis, the welfare loss from mitigation cost plus residual climate risks, compared to the no-climate-policy option, is approximately $4.3 \%$ (in terms of balanced growth equivalent), while being reduced more than $90 \%$ under a joint-mitigation-SRM analysis.
\end{abstract}

Keywords Climate targets $\cdot$ Cost-risk analysis $\cdot$ Decision making under uncertainty $\cdot$ Mitigation $\cdot$ Solar-radiation management

\section{Introduction}

Aerosol solar radiation management (SRM) gained prominence as a climate policy option through the study by Crutzen [1]. SRM is defined as any deliberate large-scale manipulation of the planetary albedo to reduce surface temperature and counteract the risks of climate change caused by greenhouse gas (GHG) emissions [2,3]. Aerosol SRM is claimed to be technically feasible and, compared to other climate policy options, a relatively inexpensive way to quickly

Elnaz Roshan

elnaz.roshan@uni-hamburg.de

1 Research Unit Sustainability and Global Change, University of Hamburg, Grindelberg 5, 20144 Hamburg, Germany

2 Department of Economic and Infrastructure Policy (WIP), The Technical University of Berlin, Strasse des 17. Juni 135, 10623 Berlin, Germany offset anthropogenic global warming [1, 4-9]. However, severe potential side effects are identified for SRM, such as a mismatch in global mean temperature and global mean precipitation compensation, ozone depletion, and a mismatch in spatial patterns of various climate variables [1, 2, 10-17]. While most extant SRM literature has discussed these in isolation, here we start with the hypothesis that society will make decisions on SRM in weighing them against costs and risks in view of alternative climate policy options, such as mitigation. Therefore, we strive for an integrated analysis of SRM and mitigation by pursuing a welfare-based portfolio approach.

In fact, [18] evaluated SRM in conjunction with mitigation for a limited set of pre-defined, RCP-inspired mitigation scenarios, and investigated the role of SRM in meeting a pre-defined temperature target, depending on the degree of mitigation encapsulated in the scenario, as well as climate sensitivity (linking equilibrium temperature rise and greenhouse gas concentration). They found that the contribution 
of SRM increases with climate sensitivity, while mitigation and SRM act as substitutes. However, they did not seek welfare-optimal portfolios of mitigation and SRM.

This, in turn, was done by [4, 19-22], and [23], who implemented SRM jointly with mitigation in a cost-benefit analysis (CBA), the axiomatically most developed decisionanalytic framework thus far. Here, we follow an alternative approach in utilizing a global temperature target as an entrypoint for further analysis. We do so for two reasons. Firstly, some fraction of the climate economists' community asserts that currently applying CBA to the climate problem carries conceptual difficulties. Extant deep uncertainties regarding the necessary global warming impact function and imprecise weighing of the costs and benefits would lead to rather non-robust results $[24,25]$. Therefore, additional studies on global warming impacts and their valuation might be requisite, at least to determine a probabilistic representation of the aggregate global warming impact function. Instead, compliance with an environmental target can be interpreted as an operationalization of the precautionary principle in view of deep uncertainty. Secondly, one could take temperature targets embraced at the latest Conferences of the Parties [26] as boundary conditions, and elucidate a cost-efficient scenario to comply with this environmental boundary condition (cost effectiveness analysis, CEA). In fact, on the order of a thousand scenarios are assembled in the latest IPCC report [27], that are based on climate targets in conjunction with CEA, rather than on CBA. Emmerling and Tavoni [22], Arino et al. [28], Ekholm and Korhonen [29], Stankoweit et al. [30], and Khabbazan et al. [31] evaluated SRM together with mitigation applying CEA. With this article, we aim to serve those readers who acknowledge value in utilizing climate targets as entry assumptions for further economic analysis.

In the following, we generalize the target concept to simultaneously cover the currently most discussed potential side effect of SRM, and an infinitely tailed probability density function on climate sensitivity. For this article, we focus on the following side effect. SRM might perfectly or in part compensate for greenhouse gases in terms of global mean temperature, but might prove unable to simultaneously do so for other climate variables, such as precipitation. The underlying reason is that SRM and greenhouse gases act on the climate system through different spatial symmetries. For this reason, for several climate variables, applying SRM destroys their scaling with global mean temperature. Consequently, for those variables, global mean temperature anomaly without specifying the cause of the anomaly, i.e. carbon dioxide vs. SRM, ceases to constitute a useful environmental proxy. Therefore, we focus on global mean precipitation as one additional climate variable that would be detached from global mean temperature through SRM. This builds a methodological extension to link the scientific community's understanding of key environmental side effects of
SRM and the policymakers' need for decision making based on the current best available information. While considering regional precipitation is closer to the society's need for policymaking, here we demonstrate a concept for the global case which allows for a more transparent and tractable analytical and numerical analysis. Thus, results of a globally aggregated analysis presented in this investigation should be interpreted with caution because main side effect of SRM arises with regionalization.

In order to tackle this problem, yet remain as close to the target concept as possible, [30, 31] suggested not to completely switch paradigms towards a full-fledged impact analysis, but rather to move only one step further down the impact chain. Following them, we explicitly model global precipitation and derive an explicit target for it. Similarly, we obtain this target from asking, assuming a global temperature target of $2{ }^{\circ} \mathrm{C}$, "What precipitation change would a proponent of the $2{ }^{\circ} \mathrm{C}$ temperature target have accepted before SRM was ever considered in global climate policy?" (the latter denotes a phase when the $2{ }^{\circ} \mathrm{C}$ temperature target was negotiated). In this way, we derive a $2{ }^{\circ} \mathrm{C}$-compatible precipitation target.

Furthermore, due to a long-tailed probability density distribution on climate sensitivity, it is necessary to interpret global mean temperature targets probabilistically [32, 33]. Target-based analyses, as assembled in [27], correspond to generic compliance probabilities of $1 / 2$ or $1 / 3$. However, when future learning on climate sensitivity is included in intertemporal welfare analysis, lexicographic preferences induced by targets would produce inconsistencies. In order to resolve these conceptual problems, cost-risk analysis (CRA) was proposed by [34] and operationalized by [35].

CRA is indeed a hybrid framework of CBA and CEA, which is utilized as a decision-analytic framework that allows for including targets in an economic analysis in a dynamically consistent manner, while not explicitly requiring a climate damage function. However, CRA necessarily requires a climate target as an input since the risk in this framework is defined as overshooting the climate target [35, 36], including probabilistic measures thereof.

Roshan et al. [37] evaluated the optimal SRM in conjunction with mitigation, applying CRA and considering regional disparities in the temperature and precipitation risks. However, their analysis only includes a numerical investigation which can weakly answer the basic research questions regarding the methodology and results. To the best of our knowledge, hereby for the first time, we apply an analytical integrated CRA of mitigation and SRM considering climate risks, which is supported by an integrated climate-energy-economy assessment model. We seek the optimal mix of mitigation and SRM under probabilistic knowledge about climate sensitivity. This decision criterion is based on maximizing a social welfare function 
which trades off between economic costs of climate policies, here mitigation and SRM, and the risk of transgressing the climate targets. Here, we introduce two risks: the risk of temperature rise and the risk of precipitation change. SRM is a symptomatic approach that would not affect the root cause of the climate change but rather its symptoms particularly global warming. While acknowledging the importance of considering $\mathrm{CO}_{2}$ concentrations as in [23] in SRM research, our focus is on temperature target because international climate targets are articulated in global mean temperature limit. Our analysis is based on the $2{ }^{\circ} \mathrm{C}$-temperature target with $66 \%$ compliance probability, which is derived from UNFCCC's agreement in 2011 [38]. The admissible precipitation corridor is determined by those values of precipitation that can be found in the absence of SRM when increasing global mean temperature from the pre-industrial state to $2{ }^{\circ} \mathrm{C}$. Consequently, the precipitation corridor represents those deviations from pre-industrial precipitation that are compatible with the preference order, as expressed by the $2{ }^{\circ} \mathrm{C}$ target. In our analysis, climate sensitivity is the key uncertain parameter and formally represented here through a log-normal probability density distribution $[35,39,40]$.

To represent the cost-risk of joint-mitigation-SRM analysis, we apply the model MIND (model of investment and technological development) $[33,35,39,41]$ as an integrated energy-economy-climate model. Generally, MIND is a renewable-fossil distinguishable model based on a Ramsey-type macroeconomic growth model.

\section{Cost-Risk Analysis}

In order to clarify some unique concepts of CRA, we discuss the static problem. In the static minimization problem of CRA (Eq. 1), a convex decision problem is needed to prevent the local optima and switching to a different regime of optimum (under a relatively small change of emissions or climate sensitivity), which would not be in compliance with the value system of the proponents of temperature targets [35]. To ensure that this is valid for any degrees of convexity of mitigation and SRM cost functions, temperature and precipitation risk functions need to be non-concave. Linear risk metrics constitute the most conservative functions that we can choose which leads to a convex decision problem. For the mitigation cost $C_{M}$, SRM cost $C_{S R M}$, trade-off parameters $\alpha$ and $\beta$, risk due to high temperature $R T$, and risk of precipitation change $R P$, the static optimization problem reads:

$$
\operatorname{Min}\left\{C_{M}+C_{S R M}+\alpha \mathbb{E}(R P)+\beta \mathbb{E}(R T)\right\}
$$

with

$\mathbb{E}(R T)=\int f(\gamma) \Phi\left(T-T_{g}\right)\left(T-T_{g}\right) d \gamma$,

$\mathbb{E}(R P)=\int f(\gamma)\left[\Phi\left(P-P_{u b}\right)\left(P-P_{u b}\right)+\Phi\left(P_{l b}-P\right)\left(P_{l b}-P\right)\right] d \gamma$

Linear risk metrics are defined as the probability of climate targets' violation proposed by [35] for temperature risk, and we develop it for precipitation risk, which are respectively represented in Eqs. 2 and 3; $f(\gamma), \Phi, T_{g}$ , $P_{u b}$, and $P_{l b}$, respectively, refer to the probability density distribution of climate sensitivity $\gamma$, the Heaviside function ( 0 for negative arguments and 1 otherwise), the temperature target, upper-bound precipitation, and lower-bound precipitation. Uncertainty in climate response is a critical feature of the climate problem. To account for this facet, we consider probabilistic knowledge of climate sensitivity with a log-normal density distribution $f(\gamma) \sim \operatorname{Ln} \mathcal{N}(\mu, \sigma)$, in our work $\mu=0.973$ and $\sigma=0.4748$ [40], which represents a somewhat centred distribution that mediates between fat-tailed [42] and thin-tailed [43] distributions. In our numerical simulations, the sample number is 20 with equal probability within the range of 1.01 to $7.17^{\circ} \mathrm{C}$, which is chosen with the same approach as [39].

As an environmental target, we choose the temperature target of $2{ }^{\circ} \mathrm{C}$ maximum increase in global mean temperature anomaly with respect to pre-industrial climate and recognized by the UNFCCC's 15th COP in 2010. It is worth noting that we assess temperature and precipitation on the global and global-land scale, respectively. The global-land precipitation anomaly is linearly related to the global mean temperature change induced by SRM and $\mathrm{CO}_{2}$ emissions. We infer the coefficient of $\mathrm{CO}_{2}$-induced temperature change from the $\mathrm{CO}_{2}$-quadrupling experiment in [15]. We use temperature and precipitation change within the $\mathrm{G} 1$ experiment of GeoMIP and $\mathrm{CO}_{2}$-quadrupling experiment from [15] to simply derive the SRM-induced precipitation change coefficient through $\mathrm{Gl}$-abrupt $4 \times \mathrm{CO}_{2}$.

We apply a CRA-based welfare functional that would cope with SRM destroying global mean temperature as a proxy for most climate variables. In generalizing the static model, we readily obtain:

$\operatorname{Max} W=\sum_{t=0}^{t_{\text {end }}} \sum_{s_{1}}^{s_{\text {end }}} p_{s}[U(t, s)-\alpha R P(t, s)-\beta R T(t, s)] e^{-\rho t}$

where $t, s, p, U$, and $\rho$ represent time, state of the world (SOW, climate sensitivity), probability of each SOW, utility, and rate of pure time preference, respectively; and $\alpha$ and $\beta$ are the trade-off parameters. The utility function, $U$, is the commonly used constant relative risk aversion (CRRA) 
utility function $U(t, s)=L(t) \frac{\left(\frac{C(t, s)}{L(t)}\right)^{1-\varnothing}}{1-\varnothing}$, where $\frac{C(t, s)}{L(t)}$ is per capita consumption, $L(t)$ is the exogenous increasing population, and $\varnothing=2$ is the relative risk aversion parameter. Furthermore, we choose a linear risk metric following the arguments discussed in $[35,36]$. Based on their discussion, this is an intuitive choice where any non-concave risk function is admissible, which is in-line with the preference order of a temperature target advocate and would prevent multiple optima of the welfare functional. A linear risk metric, however, is the most conservative and thus informative one. The risk metric in the CRA is a mathematical model of a decision-maker's attitude towards the temperature target, once the economic pressure becomes 'too large' i.e. if certain emission limits would have been violated or if climate sensitivity would have been learned to be high. This is crucial as otherwise the decision maker might give up on climate policy.

CRA makes a trade-off between the costs of reducing climate warming and excess climate risk. A trade-off parameter shows how important the risk of climate change is for society [35]. Therefore, trade-off parameters are calibrated, ${ }^{1}$ such that welfare function is maximized with at least $66 \%$ probability (according to IPCC guidance note on uncertainty, the equivalent term is 'likely') of remaining below the $2{ }^{\circ} \mathrm{C}$-temperature target without considering anticipated future learning and in the absence of SRM. This is according to the 17th COP to the UNFCCC that "aggregate emissions pathways consistent with having a likely chance of holding the increase in global average temperature below $2{ }^{\circ} \mathrm{C}$ or $1.5^{\circ} \mathrm{C}$ above pre-industrial level" [38]. The calibration is simulated in a mitigation-only analysis excluding SRM because the $2{ }^{\circ} \mathrm{C}$-temperature target is a political argument in line with mitigation. Equation 4 still leaves one degree of freedom between $\alpha$ and $\beta$. In addition, the larger $\alpha$, the larger the relative weight precipitation has had in the making of the $2{ }^{\circ} \mathrm{C}$ target. This is currently a normative choice determining to what extent an explicit representation of global precipitation risk would make the precautionary approach encapsulated in the $2{ }^{\circ} \mathrm{C}$ target obsolete.

We consider three scenarios accordingly, in which for two extreme cases of temperature-risk-only and precipitationrisk-only scenarios, we only account for temperature risk and precipitation risk, respectively. As an in-between scenario, in the both-risk scenario, we use half of any of the calibrated parameters to weigh both risks equally. This choice

\footnotetext{
1 The calibration concept is based on the positive mathematical programming [44]. In the positive mathematical programming, a calibrated term is added to the optimization that forces the model to reach the optimum following the desired result. Here, the calibration process is on the basis of the preferences of a climate target community.
}

of scenarios is in order to follow a convex combination in accounting for temperature and precipitation risks in the decision profile. This means that the weight of one risk can be increased only if the other risk's weight is reduced. While precipitation is linearly related to temperature and its upper bound is $2{ }^{\circ} \mathrm{C}$-compatible, in order to avoid double counting, a convex combination of risks should be taken into account; otherwise, $66 \%$ compliance would not be recovered.

The convex combination of expected discounted temperature and precipitation risks can be written as follows:

$R_{\text {total }}=\sum_{t=0}^{t_{\text {end }}} \sum_{s_{1}}^{s_{\text {end }}} p_{s}[\epsilon \beta R T(t, s)+(1-\epsilon) \alpha R P(t, s)] e^{-\rho t}$.

In this equation, the combination parameter, $\epsilon$, shows the weight of each risk from 0 to 1 . Scenarios in this study present three combinations of risks for $\epsilon$ that equal $0,1 / 2$, and 1 (see Fig. 8 in Appendix 1, which shows the sensitivity analysis on 100 different values of $\epsilon$ ranging between 0 and 1 in a mitigation-only analysis).

\section{A Stylized Theoretical Model}

\section{1 $\beta$ Calibration}

Before presenting numerical results, to guide intuition, we first introduce a stylized static model representing a simplification of the decision problem as expressed by Eq. 4. For this, we firstly derive a theoretical solution for the trade-off parameter in the cost-risk framework. To do so, for conceptual clarity, we use the static CRA in the temperature-riskonly scenario of the mitigation-only analysis. For mitigation cost $C_{M}\left(E_{\mathrm{CO}_{2}}\right)$ as a function of $\mathrm{CO}_{2}$ cumulative emissions $E_{\mathrm{CO}_{2}}\left(C^{\prime}{ }_{M}\left(E_{\mathrm{CO}_{2}}\right) \leq 0, C^{\prime \prime}{ }_{M}\left(E_{\mathrm{CO}_{2}}\right) \geq 0\right)$, a temperature anomaly $T=\gamma \quad \gamma \quad E_{\mathrm{CO}_{2}}$, and temperature risk $R T\left(E_{\mathrm{CO}_{2}}\right)$, the minimization problem in this scenario reads:

$\operatorname{Min}_{E_{\mathrm{CO}_{2}}}$ for $l:=C_{M}\left(E_{\mathrm{CO}_{2}}\right)+\beta \mathbb{E}\left(R T\left(E_{\mathrm{CO}_{2}}\right)\right)$.

In this equation, temperature is the only variable that depends on climate sensitivity $\gamma$, the knowledge of which we express through a log-normal probability density distribution $f$.

As explained in the previous section, the calibration of the trade-off parameter is performed in accordance with the statement of the COP17 to reach a minimum safety of $66 \%$ $\left(p_{g}\right)$ probability of compliance with the $2{ }^{\circ} \mathrm{C}$-temperature target $\left(T_{g}\right)$. Hereby, the subscript ' $g$ ' denotes 'guardrail'. Similar to [45], by minimizing Eq. 6 to reach this calibration goal, $\beta$ equals: 
$\beta=-\frac{C^{\prime}{ }_{M}\left(E_{C_{2}, g}\right)}{\frac{d}{d E_{C O_{2}}} \mathbb{E}\left(R T\left(E_{C_{2}, g}\right)\right.}$.

When determining a Taylor expansion of the cost function at the business-as-usual (BAU) emission level, the leading order must be the quadratic one. By definition, BAU is a scenario without any climate policy. It represents a scenario where the decision maker ignores climate risks. This ensures that BAU is optimal in the absence of climate risk. Thus, the mitigation cost function can be written in the following form:

$C_{M}\left(E_{\mathrm{CO}_{2}}\right)=k\left(E_{\mathrm{CO}_{2}}-E_{\mathrm{BAU}}\right)^{2}$.

We now derive a calibrated version of $\beta$ for later numerical estimations. For this, the expected temperature risk needs to be calculated as follows:

$\mathbb{E}\left[R\left(T\left(E_{\mathrm{CO}_{2}}\right)\right)\right]=\int_{\gamma_{g}}^{\infty}\left(T-T_{g}\right) f(\gamma) d \gamma$,

$$
\begin{aligned}
\mathbb{E}\left[R\left(T\left(E_{C O_{2}}\right)\right)\right]= & \frac{1}{2}\left(a e^{\mu+\frac{\sigma^{2}}{2}} E_{C O_{2}}\left(1+\operatorname{Erf}\left[\frac{\mu+\sigma^{2}-L n \gamma_{g}}{\sqrt{2} \sigma}\right]\right)\right. \\
& \left.+T_{g}\left(-2+E r f c\left[\frac{\mu-L n \gamma_{g}}{\sqrt{2} \sigma}\right]\right)\right)
\end{aligned}
$$

From this, ${ }^{2}$ we can calculate $\beta$ as follows:

$$
\beta=\frac{4 k\left(E_{B A U}-E_{C O_{2}, g}\right)}{a e^{\mu+\frac{\sigma^{2}}{2}}\left(1+E r f\left[\frac{\mu+\sigma^{2}-L n \gamma_{g}}{\sqrt{2} \sigma}\right]\right)} .
$$

\subsection{Joint-Mitigation-SRM Analysis: Optimal Emissions, Optimal SRM Forcing, and Minimum Climate Sensitivity}

Here, we continue the theoretical solution to determine optimal emissions and SRM forcing in the cost-risk framework. Considering probabilistic climate sensitivity, we can provide information about the borderline climate sensitivity, for which the temperature threshold might be trespassed when we apply SRM. Similarly, we use the static CRA of the temperature-risk-only scenario while including SRM. We utilize the above assumptions on the mitigation cost function. For the SRM cost function $C_{S R M}\left(F_{S R M}\right)$, we choose the SRM forcing $F_{S R M}$ as a variable with $C_{S R M}^{\prime}\left(F_{S R M}\right) \geq 0$. The temperature risk then reads $R T\left(E_{\mathrm{CO}_{2}}, F_{S R M}\right)$, and the minimization problem is as follows:

$$
\begin{aligned}
\operatorname{Min}_{E_{\mathrm{CO}_{2}}, F_{S R M}} l \text { for } l:= & C_{M}\left(E_{\mathrm{CO}_{2}}\right)+C_{S R M}\left(F_{S R M}\right) \\
& +\beta \mathbb{E}\left(R T\left(E_{C_{2}}, F_{S R M}\right)\right)
\end{aligned} \text {. }
$$

For $T=\gamma\left(a E_{\mathrm{CO}_{2}}-h F_{S R M}\right)$, expected temperature risk, shown in Eq. 2, can be rewritten as $\mathbb{E}(R T)=\int_{\gamma_{g}}^{\infty}\left(T-T_{g}\right)$ $f(\gamma) d \gamma$, where $\gamma_{g}$ is the minimum climate sensitivity for which temperature risk exists. This means that $\gamma_{g}$ is where $T>T_{g}$ (i.e., $\gamma\left(a E_{C_{g} O_{2}}-h F_{S R M}\right)>T_{g} \rightarrow \gamma>\frac{T_{g}}{a E_{C O_{2}}-h F_{S R M}}$, $\left.\gamma_{g}=\frac{T_{g}}{a E_{\mathrm{CO}_{2}}-h F_{S R M}}\right)$. Therefore, the expanded minimization problem, $l$, reads:

$$
\begin{aligned}
l= & C_{M}\left(E_{\mathrm{CO}_{2}}\right)+C_{S R M}\left(F_{S R M}\right)+\beta \int_{\gamma_{g}}^{\infty} . \\
& \left(\gamma a E_{\mathrm{CO}_{2}}-\gamma h F_{S R M}-T_{g}\right) f(\gamma) d \gamma
\end{aligned}
$$

The first-order condition for this two-variable problem is as follows:

$$
\begin{aligned}
& \frac{\partial l}{\partial E_{\mathrm{CO}_{2}}}=C^{\prime}{ }_{M}\left(E_{\mathrm{CO}_{2}}\right)+\beta a \int_{\gamma_{g}}^{\infty} \gamma f(\gamma) d \gamma=0 \\
& \frac{\partial l}{\partial F_{S R M}}=C_{S R M}^{\prime}\left(F_{S R M}\right)-\beta h \int_{\gamma_{g}}^{\infty} \gamma f(\gamma) d \gamma=0 .
\end{aligned}
$$

From Eqs. 14 and 15, we know that the optimum will be where:

$h C^{\prime}{ }_{M}\left(E_{C_{2}}\right)=-a C_{S R M}^{\prime}\left(F_{S R M}\right)$.

In analogy to the mitigation cost function, we now determine the leading order term of Taylor expansion at BAU for the SRM cost function. As the SRM forcing cannot be positive, it is here the linear term that ensures BAU is optimal in the absence of climate risk. Therefore, assuming a quadratic mitigation cost function and a linear SRM cost function, respectively, such as:

$C_{M}\left(E_{\mathrm{CO}_{2}}\right)=k\left(E_{\mathrm{CO}_{2}}-E_{B A U}\right)^{2}$,

$C_{S R M}\left(F_{S R M}\right)=q F_{S R M}$

the obtained solution for $E_{\mathrm{CO}_{2}}$ at the optimum by exploiting Eqs. 17 and 18 in Eq. 16 can be written in the following form:

$$
E_{C O_{2}}=E_{B A U}-\frac{a q}{2 k h} \text {. }
$$

\footnotetext{
${ }^{2}$ Note that the complement error function of $\mathrm{x}, \operatorname{Erfc}[x]$, equals $1-\operatorname{Erf}[x]$, where $\operatorname{Erf}[x]$ is the error function of $\mathrm{x}$.
} 
Fig. 1 Optimal emissions (a) and minimum climate sensitivity (b) against SRM costs derivative, for which temperature risk exists in a temperaturerisk-only scenario

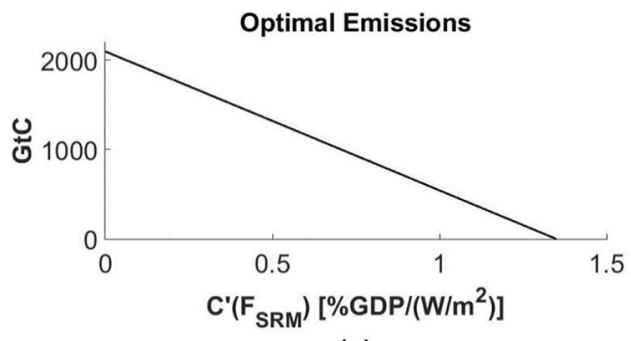

(a)

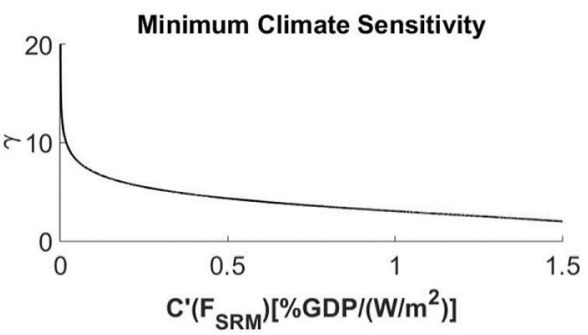

(b)
For vanishing SRM cost, optimal emissions approach BAU emissions. To calculate the optimal SRM forcing, we solve Eq. $15,{ }^{3}$ and we obtain:

$F_{S R M}=\frac{a}{h}\left(E_{B A U}-\frac{a q}{2 k h}\right)-\frac{T_{g}}{h} e^{\sqrt{2} \sigma \text { InverseErf }\left[\frac{2 q}{\beta h E(\gamma)}-1\right]-\mu-\sigma^{2}}$.

For a scenario with very low (near zero) SRM cost, the optimal SRM forcing would be equal to $\frac{a}{h} E_{B A U}$, where $E_{\mathrm{CO}_{2}}=E_{B A U}$. This means that SRM will perfectly compensate for temperature rise from emissions.

In theory, in the cost-risk analysis of the joint-mitigation SRM, the following question may arise, "What is the borderline climate sensitivity for which the temperature threshold might be trespassed in a temperature-risk-only scenario?" As explained earlier in this section, we know that $\gamma_{g}=\frac{T_{g}}{a E_{\mathrm{CO}_{2}}-h F_{S R M}}$. We now solve this equation to derive $\gamma_{g}$ :

$\gamma_{g}=e^{\mu+\sigma^{2}-\sqrt{2} \sigma \text { InverseErf }\left[\frac{2 C_{S R M}^{\prime}\left(F_{S R M}\right)}{\beta h \mathbb{E}(\gamma)}-1\right]}$.

We can see in this equation that SRM cost is a significant factor in determining the borderline climate sensitivity. Minimum climate sensitivity, for which the temperature target would be transgressed, goes toward infinity for near zero SRM cost. (See Fig. 1).

\subsection{Approximate Estimation}

\subsubsection{Calibrated $\beta$}

In this section, we prepare a test to determine to what extent our static model can emulate the dynamic analogue model MIND. Consequently, we utilize MIND parameters to estimate the calibrated $\beta$ shown in Eq. 11.

To estimate $\beta$, we first calculate $\gamma_{g}$ in the mitigation-only portfolio. In CRA, calibration is performed such that temperature remains below the temperature target with at least a $66 \%\left(=p_{g}\right)$ probability of safety. Therefore, for probability $p$ and cumulative density function $F(\gamma)$ of a log-normal distribution, we have:

\footnotetext{
3 The complete solution to solve Eq. 15 is explained in Appendix 2.
}

$F(\gamma)=\left(\frac{1}{2}\right) \operatorname{Erfc}\left[\frac{\mu-\operatorname{Ln} \gamma}{\sigma \sqrt{2}}\right]$,

$p_{g}=F\left(\gamma_{g}\right)$

$\gamma_{g}=F^{-1}\left(p_{g}\right)$

$\gamma_{g}=3.22^{\circ} \mathrm{C}, \quad$ for $p_{g}=0.66$.

The emissions for the $2{ }^{\circ} \mathrm{C}$-temperature policy and the nopolicy (BAU) are, respectively, obtained from the time-averaged cumulative emissions' results in the MIND model with accumulation starting in 2010. In the temperature equation,

$T=\gamma a E_{\mathrm{CO}_{2}}$

we can calculate $a=0.00092 \mathrm{GtCO}_{2}^{-1}$ given the information that we have for a $2{ }^{\circ} \mathrm{C}$-temperature policy.

Capital letters indicate static and, in some sense timeaveraged, quantities of time-dependent variables. For economic variables that experience quasi-exponential growth, we suggest exponential discounting in the course of aggregation. Therefore, for production $y(t)=\bar{y} e^{\lambda t}$ and its relative change $\frac{\Delta y(t)}{y(t)}=-\omega t e^{-n t}$, we define:

$\Delta Y:=\frac{\int_{0}^{\infty}-\omega y(t) t e^{-n t} e^{-s t} d t}{\int_{0}^{\infty} e^{-s t} d t}=-\frac{\omega \bar{y} s}{(s+n-\lambda)^{2}}$,

$Y:=\frac{\int_{0}^{\infty} \bar{y} e^{\lambda t} e^{-s t} d t}{\int_{0}^{\infty} e^{-s t} d t}=\frac{\bar{y} s}{s-\lambda}$.

Parameters in the exponential production function are calculated through an exponential fitting regression of model output for a BAU analysis (see Fig. 2a). In addition, $n$ within the relative production change is the inverse time period to peak the maximum output loss in a mitigation-only analysis compared to a BAU analysis (Fig. 2b). 


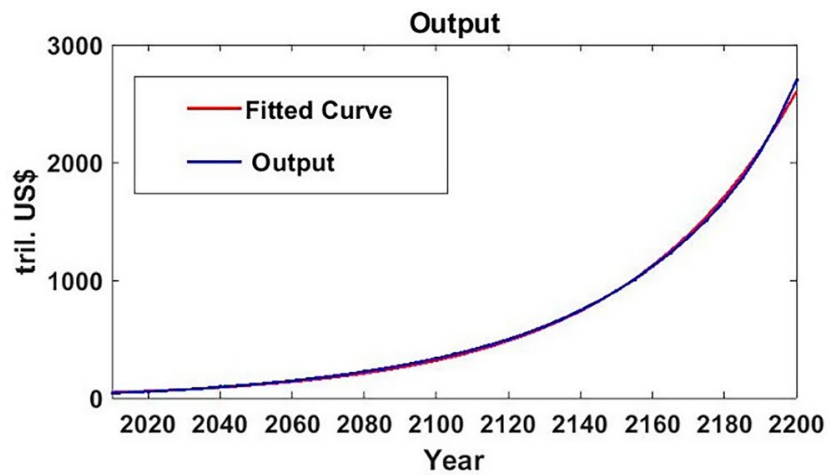

(a)

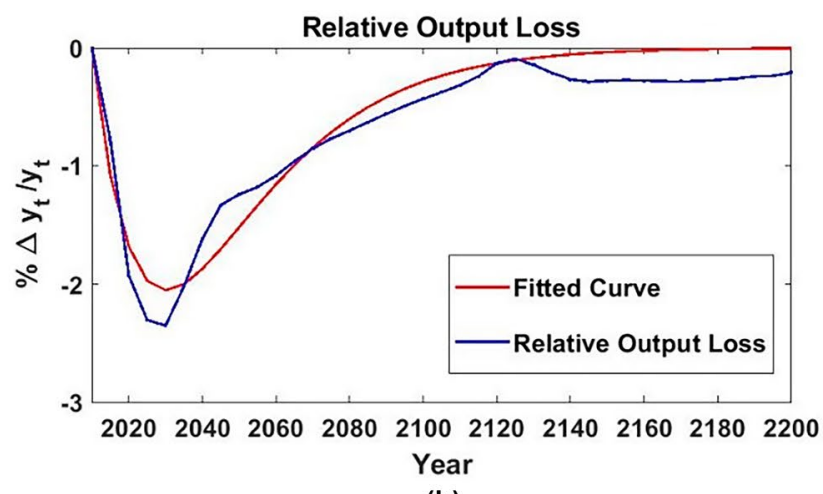

(b)

Fig. 2 Exponential fitted output (a) and relative output change in mitigation-only portfolio with regard to BAU analysis (b)

Using information that we have so far, we can calculate $C_{M}\left(E_{C_{2}}\right)=\left|\frac{\Delta Y}{Y}\right|=\frac{\omega(s-\lambda)}{(s+n-\lambda)^{2}}$ and $k=\frac{C_{M}\left(E_{\mathrm{CO}_{2}}\right)}{\left(E_{\mathrm{CO}_{2}}-E_{B A U}\right)^{2}}$. We now possess all of the information needed to estimate $\beta=1.3 \% \mathrm{GDP} /{ }^{\circ} \mathrm{C}$.

\subsubsection{Optimal Emission, Optimal SRM Forcing, and Minimum Climate Sensitivity}

Here, we can estimate optimal emissions, optimal SRM forcing, and minimum climate sensitivity derived, respectively, as follows:

$E_{\mathrm{CO}_{2}}=E_{B A U}-\frac{a q}{2 k h}=2035.12 \mathrm{GtCO}_{2}$

$$
\begin{aligned}
& F_{S R M}=\frac{1}{h}\left(a E_{\mathrm{CO}_{2}}-\frac{T_{g}}{\gamma_{g}}\right)=6.04 \mathrm{~W} / \mathrm{m} 2, \\
& \gamma_{g}=e^{\mu+\sigma^{2}-\sqrt{2} \sigma \text { InverseErf }\left[\frac{2 C_{S R M}^{\prime}\left(F_{S R M}\right)}{\beta h e^{\mu+\frac{\sigma^{2}}{2}}}-1\right]}=8.5^{\circ} \mathrm{C} .
\end{aligned}
$$

Apparently, this minimum climate sensitivity is higher than the upper range climate sensitivity of our numeric (see Fig. 9 in Appendix 3 for more information on numerical sensitivity analysis, which shows this minimum climate sensitivity in the temperature-risk-only scenario).

Numerical estimations of the model MIND used for calibrating the theoretical model are shown in Table 1.
Table 1 Numerical values used for calibrating the theoretical

\begin{tabular}{|c|c|c|c|c|c|}
\hline \multicolumn{3}{|c|}{ Climate parameters } & \multicolumn{3}{|c|}{ Economic parameters } \\
\hline Eq. 6 & $T_{g}$ & $2{ }^{\circ} \mathrm{C}$ & Eq. 28 & $n$ & $5 \% /$ year \\
\hline Eq. 11 & $\begin{array}{c}E_{\mathrm{CO}_{2}, g} \text { (mitiga- } \\
\text { tion-only) }\end{array}$ & $675.93 \mathrm{GtCO}_{2}$ & $\begin{array}{l}\text { Eq. } 28 \text {, } \\
\text { Eq. } 29\end{array}$ & $\lambda$ & $2.1 \% /$ year \\
\hline Eq. 11 & $E_{B A U}$ & $2098.59 \mathrm{GtCO}_{2}$ & $\begin{array}{l}\text { Eq. } 28 \text {, } \\
\text { Eq. } 29\end{array}$ & $s^{* * *}$ & $5 \% / y r$ \\
\hline $\begin{array}{l}\text { Eq. } 20 \text {, } \\
\text { Eq. } 21\end{array}$ & $(\mu, \sigma)$ & $(0.973,0.4748)$ & Eq. 18 & $q^{* * * * *}$ & $0.024 \% \mathrm{GDP} /\left(\mathrm{W} / \mathrm{m}^{2}\right)$ \\
\hline Eq. 23 & $p_{g}$ & $66 \%$ & Eq. 28 & $\omega$ & $0.28 \% /$ year \\
\hline Eq. 13 & $h^{* *}$ & $1 / 3.7 /\left(\mathrm{W} / \mathrm{m}^{2}\right)$ & Eq. 8 & $k$ & $6.4284 \times 10^{-7} \% \mathrm{GDP} /\left(\mathrm{GtCO}_{2}\right)^{2}$ \\
\hline Eq. 27 & $a$ & $0.0009 \mathrm{GtCO}_{2}^{-1}$ & & & \\
\hline Eq. 25 & $\gamma_{g}^{2^{\circ} \mathrm{C}, 66 \%}$ & $3.22{ }^{\circ} \mathrm{C}$ & & & \\
\hline
\end{tabular}
model
${ }^{*}$ Cumulative emissions are averaged over the time period 2010-2200

** According to [46], $h$ equals the reciprocal of the radiative forcing induced by a doubling of the concentration of $\mathrm{CO}_{2}$ with respect to its pre-industrial value

${ }^{* * * *}$ Social discount rate, $\boldsymbol{s}$, is calculated utilizing the Ramsey equation $s=\rho+\lambda \boldsymbol{\eta}$, where $\rho, \lambda$, and $\boldsymbol{\eta}$ are, respectively, pure rate of time preference (1\%/year), production growth rate ( $2 \%$ /year), and constant relative risk aversion (2)

**** SRM cost parameter, $q$, is calibrated from upper bound estimation of [47] as a percentage change in annual global GDP of \$50 trillion [19] from World Bank, World Development Indicator 
BAU, Temperature- \& Precipitation-Risk-Only

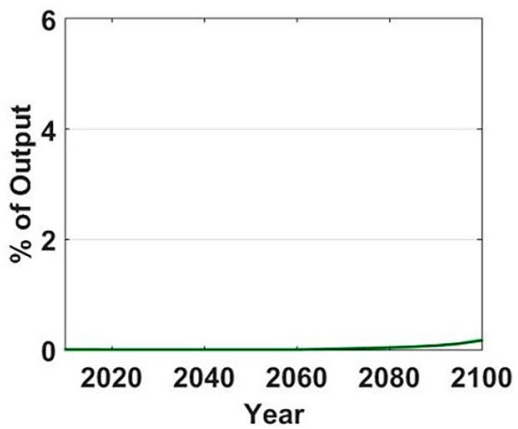

(a)
Mitigation-Only

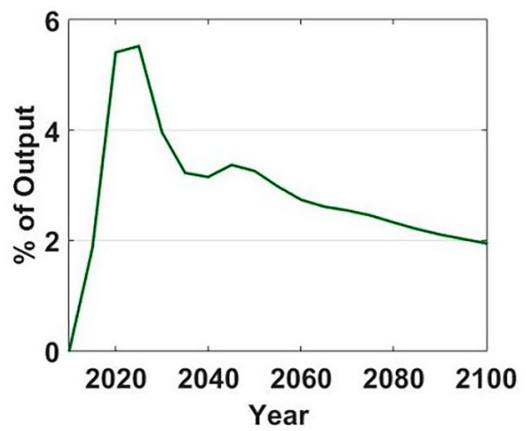

(b)
Both-Risks

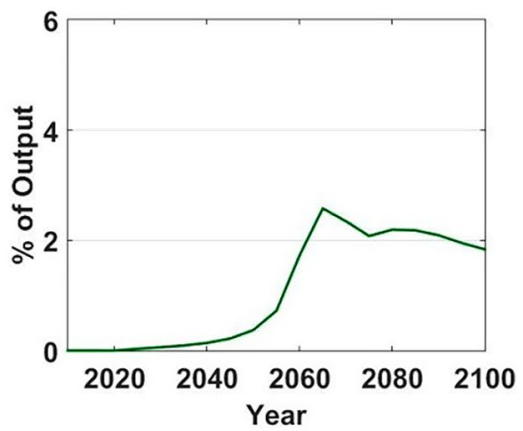

(c)
Fig. 3 Investment in renewables. In temperature- and precipitationrisk-only scenarios, mitigation would be crowded out (a) while in both-risks scenarios (c), the starting point of investment on renewa- bles would be approximately 30 years earlier than BAU analysis (a), but still 30 years later than mitigation-only analysis (b)

to their thresholds at all times. This is where SRM might be considered as a climate policy option to help avert the $2{ }^{\circ} \mathrm{C}$ transgressions.

By adding SRM to the portfolio, we again consider the temperature-risk-only, precipitation-risk-only, and both-risks scenarios (Fig. 6). Figure 6a and a*) represent

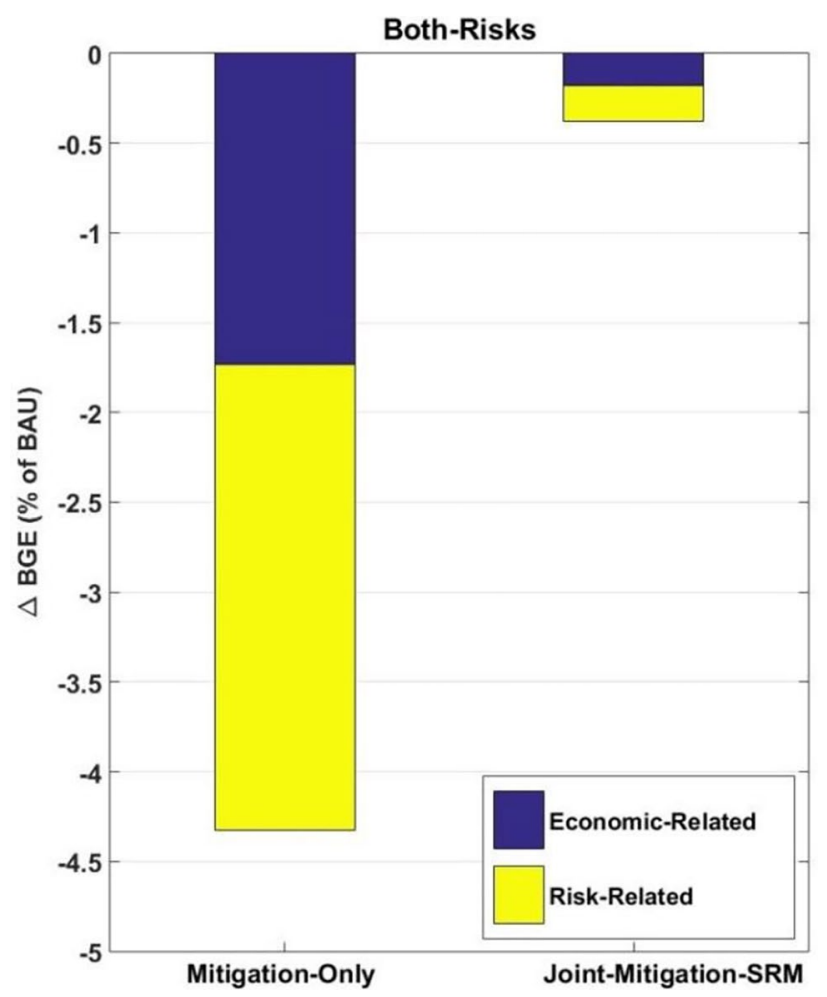

Fig. 4 Welfare loss (in terms of BGE) in the both-risks scenario from climate risks and economic costs for the mitigation-only and jointmitigation-SRM portfolio. This shows that by adding SRM to the mitigation portfolio, more than $90 \%$ of welfare loss due to temperature and precipitation risks and mitigation cost can be conserved 
Fig. 5 Temperature $(\mathbf{a}, \mathbf{b})$ and precipitation $\left(\mathbf{a}^{*}, \mathbf{b}^{*}\right)$ change with respect to the preindustrial level for 20 different states of the world from blue (low climate sensitivity) to red (high climate sensitivity). Left and right graphs represent scenarios for the BAU and mitigationonly portfolios, respectively. Dashed lines show the relevant target. In the BAU analysis, both temperature and precipitation targets would be transgressed for most of the SOWs, while they comply with their targets for approximately $66 \%$ of SOWs in the mitigation-only portfolio by construction

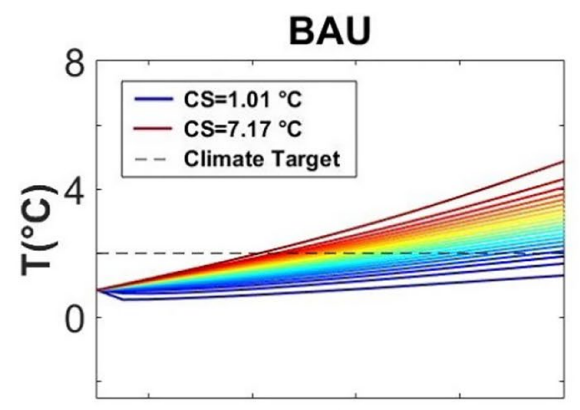

(a)

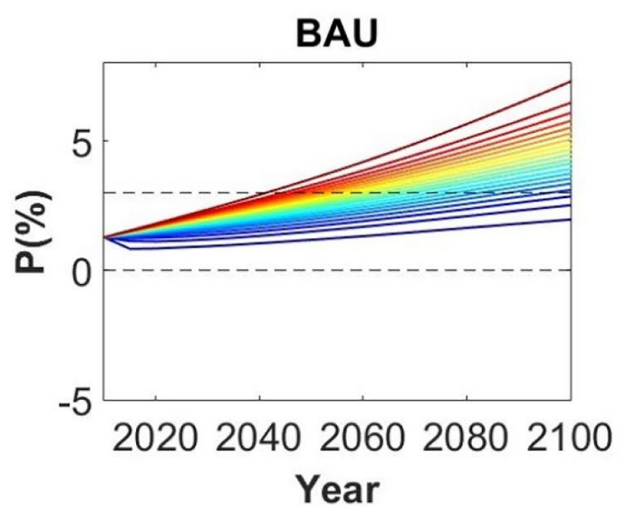

$\left(a^{*}\right)$

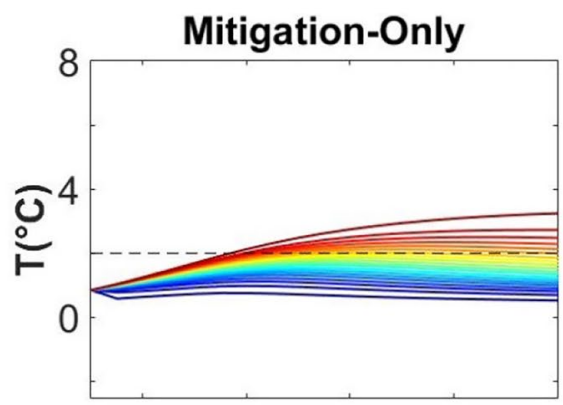

(b)

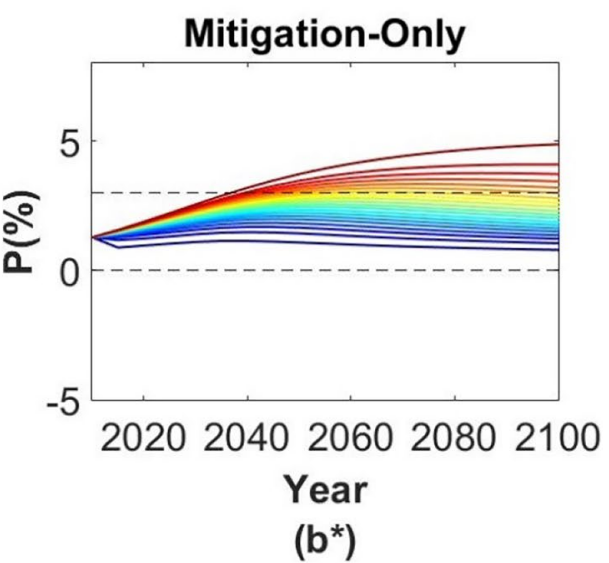

temperature-risk-only scenarios, in which SRM is added to the portfolio but its side effects are not taken into account. In this scenario, we obtain perfect compliance with the $2{ }^{\circ} \mathrm{C}$-temperature target for all of the SOWs. This is a feature that is impossible to achieve without SRM. The "borderline" climate sensitivity value for which a transgression would still occur is determined by equalizing the marginal welfare gain from avoiding climate risk through an extra unit

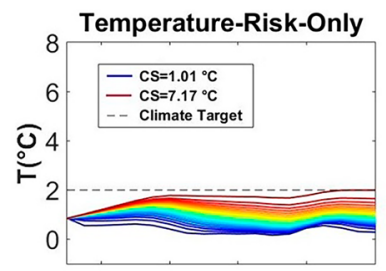

(a)

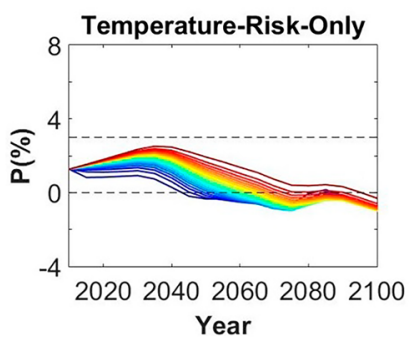

$\left(a^{*}\right)$

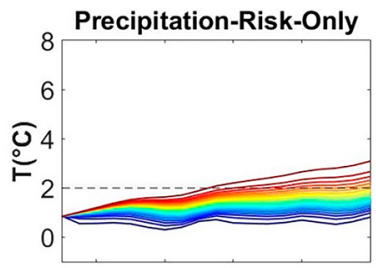

(b)

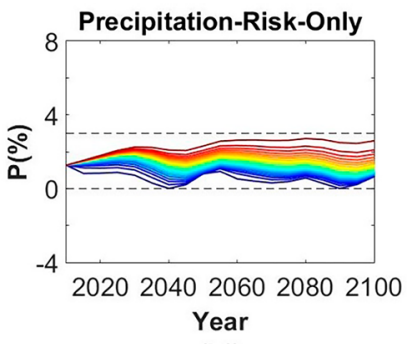

$\left(b^{*}\right)$

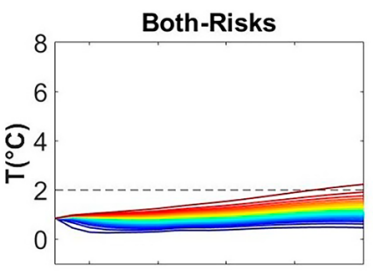

(c)

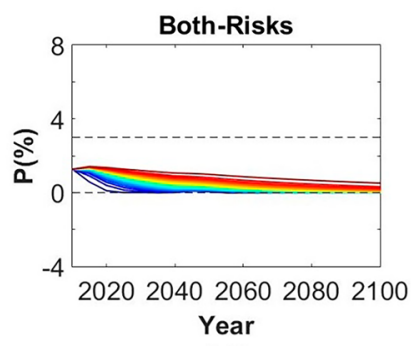

$\left(c^{*}\right)$
Fig. 6 Temperature $(\mathbf{a}, \mathbf{b}, \mathbf{c})$ and precipitation $\left(\mathbf{a}^{*}, \mathbf{b}^{*}, \mathbf{c}^{*}\right)$ change from preindustrial climate in the joint-mitigation-SRM analysis for 20 different states of the world from blue (low climate sensitivity) to red (high climate sensitivity). Left, middle, and right graphs represent trends for temperature-risk-only, precipitation-risk-only, and both-risks, respectively. Dashed lines show the relevant target. In the temperature-risk-only scenario, perfect compliance with the temperature target can be achieved, but the precipitation target is violated. The precipitation-risk-only and both-risks scenarios exhibit perfect compliance with the precipitation target, while the temperature target is transgressed 
Fig. 7 Division of temperature $(\mathbf{a}, \mathbf{b}, \mathbf{c})$ and precipitation $\left(\mathbf{a}^{*}\right.$, $\mathbf{b}^{*}, \mathbf{c}^{*}$ ) changes into the $\mathrm{CO}_{2}-$ and SRM-induced changes. Top figures divide temperature change in the temperature-riskonly scenario into the $\mathrm{CO}_{2}$ - and SRM-induced changes. Lower figures display $\mathrm{CO}_{2}$ - and SRMinduced precipitation changes in the both-risks scenario. As shown, SRM-induced changes are in a manner that compensates for all of the changes induced by $\mathrm{CO}_{2}$, and thus this compensation is more for higher climate sensitivities

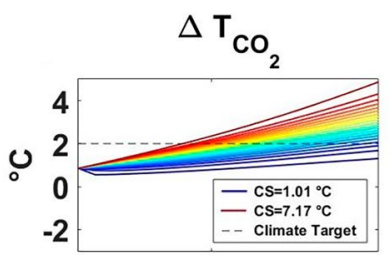

(a)

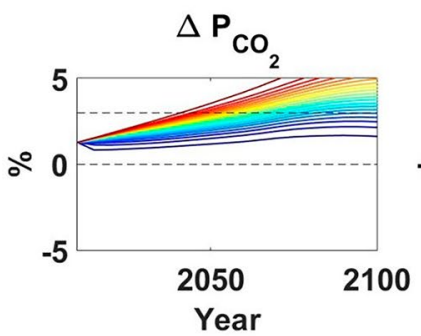

$\left(a^{*}\right)$

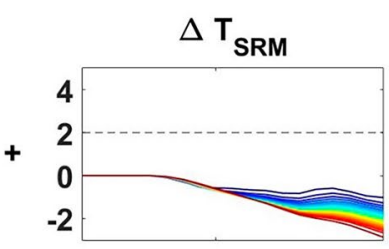

(b)

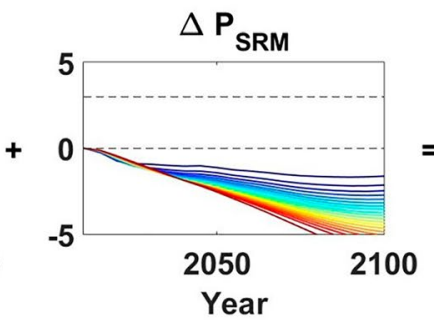

(b*)
$\Delta \mathrm{T}$

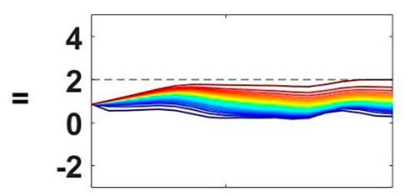

(c)

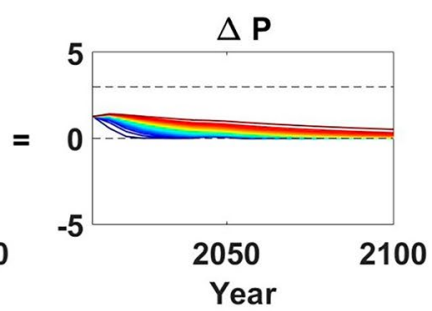

$\left(c^{*}\right)$ of SRM, and per-unit SRM costs. The former, in turn, will depend on the properties of the probability density function of climate sensitivity. Apparently, the above borderline value of climate sensitivity is larger than our resolved upper end as of $7.17^{\circ} \mathrm{C}$ (see Fig. 9 in the Appendix 3).

However, precipitation violates its lower bound for all SOWs by the end of the century. Precipitation declines more dramatically for those with higher climate sensitivities than those with lower climate sensitivities. SRM reduces temperature risk by compensating the $\mathrm{CO}_{2}$-induced temperature rise, which is greater for higher climate sensitivities. Therefore, SRMinduced temperature and precipitation reductions are larger when climate sensitivity is higher (see upper graphs in Fig. 7).

In contrast, in the precipitation-risk-only scenario in which only the precipitation risk is activated (Fig. $6 \mathrm{~b}$ and $\left.b^{*}\right)$, the temperature guardrail is transgressed for approximately $30 \%$ of SOWs in the joint-mitigation-SRM analysis by the end of the century, while precipitation lies in its acceptable range for all SOWs. In Fig. 6c and c*), which display the results of the both-risk scenario in which both precipitation and temperature risks are activated with equal weights, almost $90 \%$ and perfect compliance, respectively, with temperature target and precipitation corridor, can be achieved for the time horizon until 2100. $\mathrm{CO}_{2}$ - and SRMinduced precipitation changes in this scenario are shown in the lower graphs of Fig. 7. As both risks are taken into the optimization problem in this scenario, both risks are minimized compared to the extreme scenarios.

\section{Conclusions}

We emphasize the need for jointly evaluating solar radiation management (SRM) and mitigation. Here, we consider precipitation mismatch as a key risk category of SRM and formalize a target-based risk-cost-risk trade-off between risks from global warming, policy costs, and risks from SRM side effects. We choose cost-risk analysis (CRA) as our decision analytic framework, as it successfully deals with both deep uncertainty on global warming- and SRMinduced damages, as well as the infinitely tailed probability density function of climate sensitivity. This investigation is a conceptual innovation to also include side effects of policy measures in the CRA-based social welfare function. By referring to global aggregates only, the present study represents the simplest-possible option for such an inclusion. Its simplicity allows for an analytic treatment of the interplay of SRM costs and target overshoot. In turn, the present study, deliberately abstaining from analyzing regional pattern mismatches, is not to be put into the context of policy advice.

CRA combines the mathematical structure of cost-benefit analysis with the target concept used in cost-effectiveness analysis. The trade-off parameters are calibrated within a universally applicable procedure, which makes a trade-off between expected welfare-loss due to mitigation costs and avoided risks of climate targets transgression considering uncertainty in reaching the climate targets. We choose a probabilistic compliance level of $66 \%$, in-line with an IPCC-calibrated language adjusted interpretation of "likely" achieving the $2{ }^{\circ} \mathrm{C}$ target [38]. We invent an extension of CRA such that it can deal with multiple climate targets, in our case precipitation target, in addition to the original temperature target. For the sake of transparency of the methodology, here we focus on the interplay of targets for globally aggregated climate variables.

To identify the optimal choice between mitigation and SRM, we utilize an integrated assessment model and develop three scenarios: two as the extreme cases when either temperature risk or precipitation risk are considered, i.e. temperature-risk-only and precipitation-risk-only, and 
one scenario which considers both risks with equal weight, called both-risks scenario. Overall, our results demonstrate that welfare-loss for the mitigation-only option compared to BAU is approximately $4.3 \%$ (BGE) due to mitigation cost and climate risk, while it is approximately $1.7 \%$ (BGE) only due to mitigation cost.

By adding SRM to the portfolio, in the temperature- and precipitation-risk-only scenarios, welfare rises approximately to its BAU level. In addition, SRM almost completely crowds out mitigation without significant welfare-loss in comparison with BAU, which can be explained by its low cost. In the temperature-risk-only scenario, perfect compliance and perfect incompliance, respectively, with temperature target and precipitation corridor can be achieved for all SOWs. In the precipitation-risk-only scenario, precipitation perfectly lies within its acceptable range for all SOWs, but temperature remains confined to its threshold for $70 \%$ of SOWs. Results of the both-risks scenario show almost $90 \%$ and perfect compliance with temperature and precipitation targets, respectively. Although SRM does not completely crowd out mitigation in this scenario, it can save $90 \%$ of welfare loss from economic costs and climate risks.

As a note of caution, we would like to highlight that we expect qualitatively different results when regional guardrails are added. In this sense, the fact that mitigation is crowded out in a joint-mitigation-SRM portfolio (in temperature- and precipitation-risk-only scenarios) could constitute a unique feature of global guardrails, which might not be robust under regionalization. Furthermore, we would like to emphasize that our analysis comprises only one out of several potential risks accompanying SRM. Thus this study is silent regarding ethical implications of SRM - being spatial (e.g. alteration of regional precipitation patterns) and intergenerational (e.g. discontinuation and abrupt termination) distributive justice or procedural justice (e.g. unilateral deployment and free driver issue) (for further information about ethics of SRM deployment see [4, $48,49]$. Here, the contribution of this work is that we merely propose a viable idea of how to generalize a single probabilistic target to multiple targets for discussion, and highlight the unique feature of SRM of achieving almost $100 \%$ compliance levels.

\section{Appendix 1}

In this section, we present the results of our sensitivity analysis for a convex combination of climate risks in the decision-making shown in Eq. 5 of the main manuscript. Figure 8 displays the total risks for 100 different values of combination parameter, $\varepsilon$, ranging from 0 to 1 . This clearly demonstrates that the total risks in a mitigation-only analysis will not change by using a convex combination of the different climate variables' risks. This assists our cost-risk analysis to add further precipitation risk in addition to temperature risk, and analyzing both risks simultaneously.
Fig. 8 Convex combination of temperature and precipitation risks. This figure shows the sensitivity analysis on combination parameter of Eq. 5 in the mitigation-only portfolio, for 100 different $\epsilon$ ranging between 0 and 1 . As shown, the convex combination of temperature and precipitation recover $66 \%$ compliance goal of calibration and prevent double counting

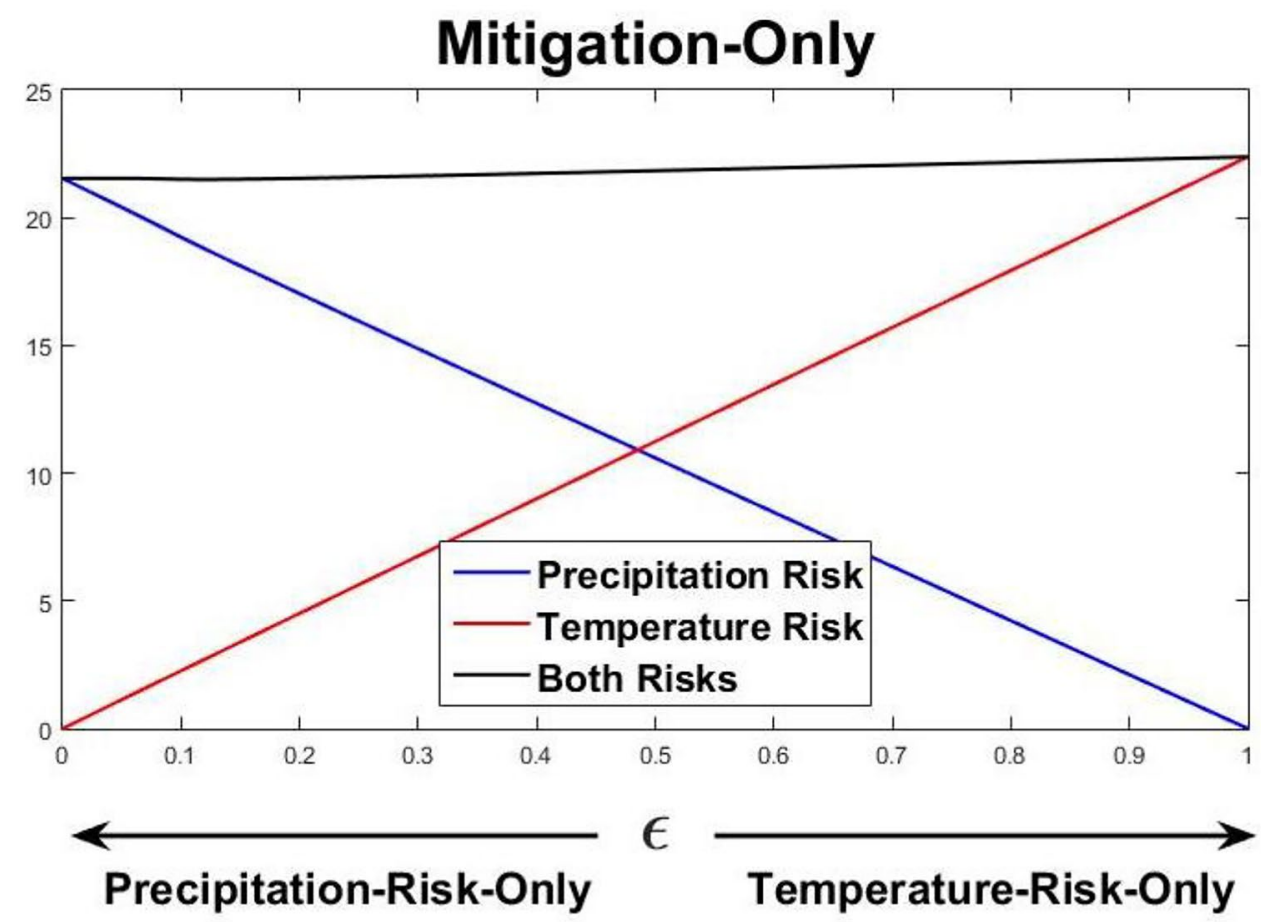




\section{Appendix 2}

Here, we can find the solution for Eq. 15 to be solved for optimal SRM forcing, $F_{S R M}$. The solutions are numbered as 32-39. Eq. 15 can be written as follows:

$\frac{C_{S R M}^{\prime}\left(F_{S R M}\right)}{\beta h}=\int_{\frac{T_{g}}{a E_{C O_{2}}-h F_{S R M}}}^{\infty} \gamma f(\gamma) d \gamma$.

In order to solve this equation for $\mathrm{F}_{\mathrm{SRM}}$, we need to expand the right-hand side integral so that we obtain:

$\int_{\frac{T_{g}}{a E_{C O_{2}} h F_{S R M}}}^{\infty} \gamma f(\gamma) d \gamma=\frac{1}{2} \mathbb{E}(\gamma)\left(1+\operatorname{Erf}\left[\frac{\mu+\sigma^{2}-\operatorname{Ln}\left(\frac{T_{g}}{a E_{C O_{2}}-h F_{S R M}}\right)}{\sigma \sqrt{2}}\right]\right)$

where $\mathbb{E}(\gamma)$ is the expected value of climate sensitivity in a $\log$-normal distribution, $\mathbb{E}(\gamma)=\mathrm{e}^{\mu+\frac{\sigma^{2}}{2}}$. Thus, to obtain $F_{S R M}$ at the optimum, Eq. 32 can be written in the following forms:

$\frac{C_{S R M}^{\prime}\left(F_{S R M}\right)}{\beta h}=\frac{1}{2} \mathbb{E}(\gamma)\left(1+\operatorname{Erf}\left[\frac{\mu+\sigma^{2}-\operatorname{Ln}\left(\frac{T_{g}}{a E_{C O_{2}}-h F_{S R M}}\right)}{\sigma \sqrt{2}}\right]\right)$

$\frac{2 C_{S R M}^{\prime}\left(F_{S R M}\right)}{\beta h \mathbb{E}(\gamma)}-1=\operatorname{Erf}\left[\frac{\mu+\sigma^{2}-\operatorname{Ln}\left(\frac{T_{g}}{a E_{\mathrm{CO}_{2}}-h F_{S R M}}\right)}{\sigma \sqrt{2}}\right]$,
InverseErf $\left[\frac{2 C_{S R M}^{\prime}\left(F_{S R M}\right)}{\beta h \mathbb{E}(\gamma)}-1\right]=\frac{\mu+\sigma^{2}-\operatorname{Ln}\left(\frac{T_{g}}{a E_{C O_{2}}-h F_{S R M}}\right)}{\sigma \sqrt{2}}$

$\operatorname{Ln}\left(\frac{T_{g}}{a E_{\mathrm{CO}_{2}}-h F_{S R M}}\right)=\mu+\sigma^{2}-\sqrt{2} \sigma$ InverseErf

$$
\left[\frac{2 C_{S R M}^{\prime}\left(F_{S R M}\right)}{\beta h \mathbb{E}(\gamma)}-1\right]
$$

$\frac{T_{g}}{a E_{\mathrm{CO}_{2}}-h F_{S R M}}=e^{\mu+\sigma^{2}-\sqrt{2} \sigma \operatorname{InverseErf[}\left[\frac{2 C_{S R M}^{\prime}\left(F_{S R M}\right)}{\beta h \mathbb{E}(\gamma)}-1\right]}$,

$F_{S R M}=\frac{1}{h}\left(a E_{C_{2}}-T_{g} e^{\sqrt{2} \sigma \text { InverseErf }\left[\frac{2 C_{S R M}^{\prime}\left(F_{S R M}\right)}{\beta h \mathbb{E}(\gamma)}-1\right]-\mu-\sigma^{2}}\right)$.

We can insert the optimal emissions $E_{\mathrm{CO}_{2}}$, Eq. 19, in Eq. 39. From this, we derive the optimal SRM forcing shown in Eq. 20.

\section{Appendix 3}

To test the accuracy of our theoretical model, we simulate the temperature-risk-only scenario for a sample of climate sensitivities that range from 1.01 to $20^{\circ} \mathrm{C}$. The result of this sensitivity analysis is displayed in Fig. 9. From this figure, it can clearly be seen that if climate sensitivity is higher than $8^{\circ} \mathrm{C}$, temperature will transgress the $2{ }^{\circ} \mathrm{C}$-temperature guardrail.
Fig. 9 Maximum temperature for different climate sensitivities in the temperature-risk-only scenario. This figure shows a numerical sensitivity analysis, for 30 different climate sensitivities within the range of 1.01 to $20^{\circ} \mathrm{C}$, to test the accuracy of our analytic solution. The filled circles display climate sensitivities for which temperature will transgress the temperature target by using SRM in the temperature-riskonly scenario

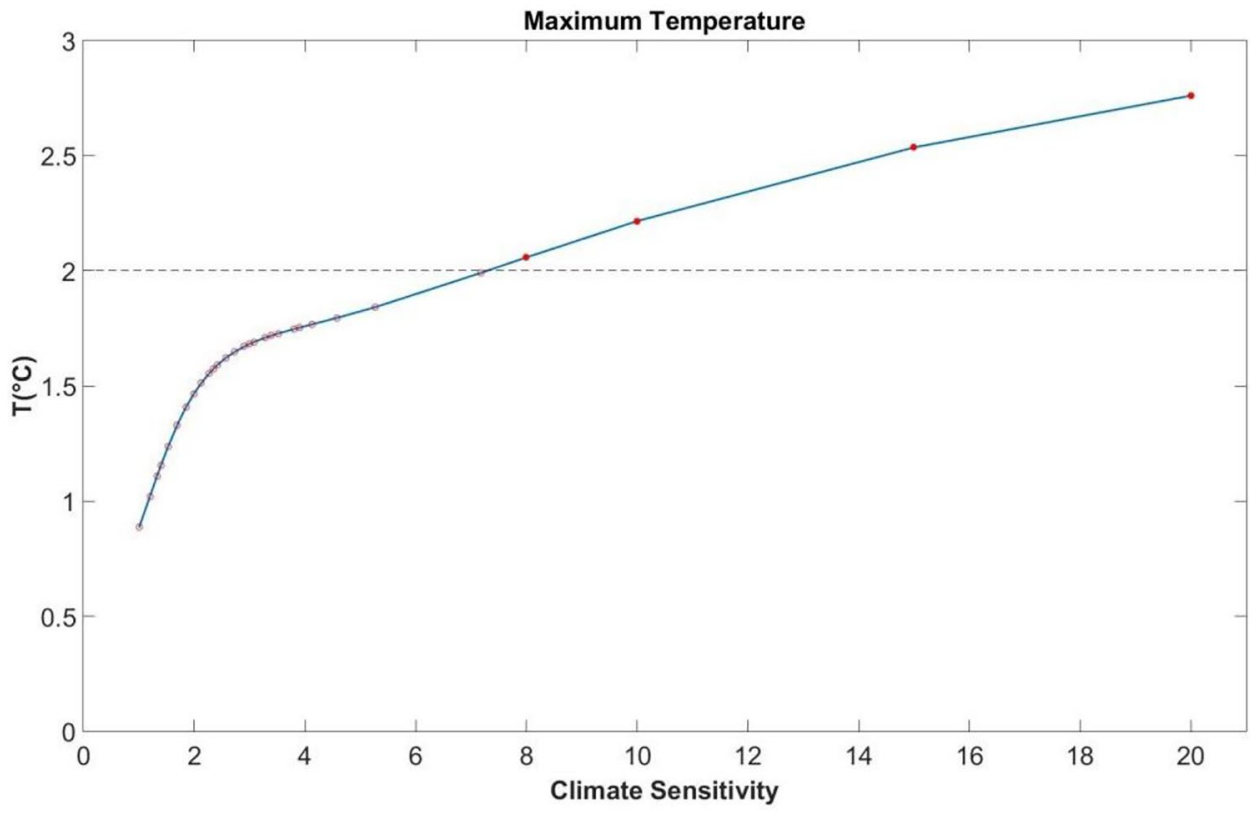


Author Contribution E.R. integrated SRM into CRA, wrote this manuscript, performed the scenario calculations, provided the numerical simulations, solved the analytic model, provided the analytical calibration and numerical emulation of the analytical model; M.M.K. and E.R. executed the numerical calibration and implemented the convex combination; M.M.K. wrote most of the calibration codes, and optimized the GAMS codes; H.H. and M.M.K. participated in revising the manuscript; H.H. triggered this work, suggested the scheme how to integrate SRM in CRA and the analytic model, and participated in revising the analytical model; and E.R. and H.H. designed the scenarios.

Funding Open Access funding enabled and organized by Projekt DEAL. This work was supported by the DFG (grant numbers HE 555812-2 and DFG-EXC177). E.R. has been supported by the DFG grant HE 555812-1 within the DFG priority program 'Climate engineering - Risks, Challenges, Opportunities' (SPP1689). M.M.K. has been supported by the DFG grant DFG-EXC177 within the Cluster of Excellence 'Integrated Climate System Analysis and Prediction' (CliSAP).

Data Availability Data can be made available on request.

Code Availability MATLAB codes, used for visualization, can be shared on request. GAMS codes, used for the scenario analyses in the model MIND [41], are not publicly open-access. Upon reasonable request, the authors will provide as much transparency as possible with the product owner's permission.

\section{Declarations}

Conflict of Interest The authors declare no competing interests.

Open Access This article is licensed under a Creative Commons Attribution 4.0 International License, which permits use, sharing, adaptation, distribution and reproduction in any medium or format, as long as you give appropriate credit to the original author(s) and the source, provide a link to the Creative Commons licence, and indicate if changes were made. The images or other third party material in this article are included in the article's Creative Commons licence, unless indicated otherwise in a credit line to the material. If material is not included in the article's Creative Commons licence and your intended use is not permitted by statutory regulation or exceeds the permitted use, you will need to obtain permission directly from the copyright holder. To view a copy of this licence, visit http://creativecommons.org/licenses/by/4.0/.

\section{References}

1. Crutzen, P. J. (2006). Albedo enhancement by stratospheric sulfur injections: A contribution to resolve a policy dilemma? Climatic Change, 77(3), 211. https://doi.org/10.1007/s10584-006-9101-y

2. Kravitz, B., Caldeira, K., Boucher, O., Robock, A., Rasch, P. J., Alterskjær, K., et al. (2013). Climate model response from the Geoengineering Model Intercomparison Project (GeoMIP). Journal of Geophysical Research: Atmospheres, 118(15), 8320-8332. https://doi.org/10.1002/jgrd.50646

3. MacMartin, D. G., Kravitz, B., \& Keith, D. W. (2014). Geoengineering: The world's largest control problem. In 2014 American Control Conference, 4-6 June 2014 (pp. 2401-2406). https://doi. org/10.1109/ACC.2014.6858658

4. Goes, M., Tuana, N., \& Keller, K. (2011). The economics (or lack thereof) of aerosol geoengineering. Climatic Change, 109(3), 719-744. https://doi.org/10.1007/s10584-010-9961-z
5. Keith, D. W. (2000). Geoengineering the climate: History and prospect. Annual Review of Energy and the Environment, 25(1), 245-284. https://doi.org/10.1146/annurev.energy.25.1.245

6. Matthews, H. D., \& Caldeira, K. (2007). Transient climate-carbon simulations of planetary geoengineering. Proceedings of the National Academy of Sciences, 104(24), 9949-9954. https:// doi.org/10.1073/pnas.0700419104

7. McClellan, J., Keith, D. W., \& Apt, J. (2012). Cost analysis of stratospheric albedo modification delivery systems. Environmental Research Letters, 7(3), 034019.

8. Robock, A., Marquardt, A., Kravitz, B., \& Stenchikov, G. (2009). Benefits, risks, and costs of stratospheric geoengineering. Geophysical Research Letters, 36(19). https://doi.org/10. 1029/2009GL039209

9. Shepherd, J., Caldeira, K., Haigh, J., Keith, D., Launder, B., Mace, G., et al. (2009). Geoengineering the climate - Science, governance and uncertainty. The Royal Society.

10. Bala, G., Duffy, P. B., \& Taylor, K. E. (2008). Impact of geoengineering schemes on the global hydrological cycle. Proceedings of the National Academy of Sciences, 105(22), 7664-7669. https://doi.org/10.1073/pnas.0711648105

11. Barrett, S., Lenton, T. M., Millner, A., Tavoni, A., Carpenter, S., Anderies, J. M., et al. (2014). Climate engineering reconsidered. Nature. Climate Change, 4(7), 527-529. https://doi.org/ 10.1038/nclimate2278

12. Kravitz, B., Rasch, P. J., Forster, P. M., Andrews, T., Cole, J. N. S., Irvine, P. J., et al. (2013). An energetic perspective on hydrological cycle changes in the Geoengineering Model Intercomparison Project. Journal of Geophysical Research: Atmospheres, 118(23), 13,087-13,102. https://doi.org/10.1002/2013JD020502

13. Lunt, D. J., Ridgwell, A., Valdes, P. J., \& Seale, A. (2008). "Sunshade World": A fully coupled GCM evaluation of the climatic impacts of geoengineering. Geophysical Research Letters, 35(12). https://doi.org/10.1029/2008GL033674

14. Robock, A., Oman, L., \& Stenchikov, G. L. (2008). Regional climate responses to geoengineering with tropical and Arctic $\mathrm{SO}_{2}$ injections. Journal of Geophysical Research: Atmospheres, 113(D16). https://doi.org/10.1029/2008JD010050

15. Schmidt, H., Alterskjær, K., Bou Karam, D., Boucher, O., Jones, A., Kristjánsson, J. E., et al. (2012). Solar irradiance reduction to counteract radiative forcing from a quadrupling of $\mathrm{CO}_{2}$ : Climate responses simulated by four earth system models. Earth System Dynamics, 3(1), 63-78. https://doi.org/10.5194/ esd-3-63-2012

16. Tilmes, S., Fasullo, J., Lamarque, J. F., Marsh, D. R., Mills, M., Alterskjær, K., et al. (2013). The hydrological impact of geoengineering in the Geoengineering Model Intercomparison Project (GeoMIP). Journal of Geophysical Research: Atmospheres, 118(19), 11,036-011,058. https://doi.org/10.1002/jgrd. 50868

17. Tilmes, S., Müller, R., \& Salawitch, R. (2008). The sensitivity of polar ozone depletion to proposed geoengineering schemes. Science, 320(5880), 1201-1204. https://doi.org/10.1126/science. 1153966

18. Smith, S. J., \& Rasch, P. J. (2013). The long-term policy context for solar radiation management. Climatic Change, 121(3), 487-497. https://doi.org/10.1007/s10584-012-0577-3

19. Moreno-Cruz, J. B., \& Keith, D. W. (2013). Climate policy under uncertainty: A case for solar geoengineering. Climatic Change, 121(3), 431-444. https://doi.org/10.1007/ s10584-012-0487-4

20. Bahn, O., Chesney, M., Gheyssens, J., Knutti, R., \& Pana, A. C. (2015). Is there room for geoengineering in the optimal climate policy mix? Environmental Science \& Policy, 48, 67-76. https:// doi.org/10.1016/j.envsci.2014.12.014 
21. Heutel, G., Moreno-Cruz, J., \& Shayegh, S. (2016). Climate tipping points and solar geoengineering. Journal of Economic Behavior and Organization, 132, 19-45. https://doi.org/10. 1016/j.jebo.2016.07.002

22. Emmerling, J., \& Tavoni, M. (2017). Climate engineering and abatement: A 'flat' relationship under uncertainty. Environmental and Resource Economics. https://doi.org/10.1007/ s10640-016-0104-5

23. Heutel, G., Moreno-Cruz, J., \& Shayegh, S. (2018). Solar geoengineering, uncertainty, and the price of carbon. Journal of Environmental Economics and Management, 87, 24-41. https:// doi.org/10.1016/j.jeem.2017.11.002

24. Kolstad, C., Urama, K., Broome, J., Bruvoll, A., Cariño Olvera, M., Fullerton, D., et al. (2014). Social, economic, and ethical concepts and methods. Climate Change 2014: Mitigation of Climate Change, Intergovernmental Panel on Climate Change. Cambridge, United Kingdom and New York, NY, USA.

25. Kunreuther, H., Gupta, S., Bosetti, V., Cooke, R., Dutt, V., HaDuong, M., et al. (2014). Integrated risk and uncertainty assessment of climate change response policies. Climate Change 2014: Mitigation of Climate Change, Intergovernmental Panel on Climate Change. Cambridge, United Kingdom and New York, NY, USA.

26. UNFCCC. (2015). Adoption of the Paris Agreement, United Nations Framework Convention on Climate Change. Geneva, Switzerland: United Nations Office.

27. Clarke, L., Jiang, K., Akimoto, K., Babiker, M., Blanford, G., Fisher-Vanden, K., et al. (2014). Assessing transformation pathways. Climate Change 2014: Mitigation of Climate Change, Intergovernmental Panel on Climate Change. Cambridge, United Kingdom and New York, NY, USA.

28. Arino, Y., Akimoto, K., Sano, F., Homma, T., Oda, J., \& Tomoda, T. (2016). Estimating option values of solar radiation management assuming that climate sensitivity is uncertain. Proceedings of the National Academy of Sciences, 113(21), 5886-5891. https://doi.org/10.1073/pnas.1520795113

29. Ekholm, T., \& Korhonen, H. (2016). Climate change mitigation strategy under an uncertain Solar Radiation Management possibility. Climatic Change, 139(3), 503-515. https://doi.org/10. 1007/s10584-016-1828-5

30. Stankoweit, M., Schmidt, H., Roshan, E., Pieper, P., \& Held, H. (2015). Integrated mitigation and solar radiation management scenarios under combined climate guardrails. In EGU General Assembly 2015, Vienna, Austria, 12-17 April 2015.

31. Khabbazan, M. M., Stankoweit, M., Roshan, E., Schmidt, H., \& Held, H. (in review, 2020). Trade-offs of solar geoengineering and mitigation under climate targets. Earth System Dynamics Discussions [preprint]. https://doi.org/10.5194/esd-2020-95

32. den Elzen, M. G. J., \& van Vuuren, D. P. (2007). Peaking profiles for achieving long-term temperature targets with more likelihood at lower costs. Proceedings of the National Academy of Sciences, 104(46), 17931-17936. https://doi.org/10.1073/pnas. 0701598104

33. Held, H., Kriegler, E., Lessmann, K., \& Edenhofer, O. (2009). Efficient climate policies under technology and climate uncertainty. Energy Economics, 31, S50-S61. https://doi.org/10. 1016/j.eneco.2008.12.012

34. Schmidt, M. G. W., Lorenz, A., Held, H., \& Kriegler, E. (2011). Climate targets under uncertainty: challenges and remedies. $\mathrm{Cli}$ matic Change, 104(3), 783-791. https://doi.org/10.1007/ s10584-010-9985-4
35. Neubersch, D., Held, H., \& Otto, A. (2014). Operationalizing climate targets under learning: An application of cost-risk analysis. Climatic Change, 126(3), 305-318. https://doi.org/10. 1007/s10584-014-1223-z

36. Held, H. (2019). Cost risk analysis: Dynamically consistent decision-making under climate targets. Environmental and Resource Economics, 72(1), 247-261. https://doi.org/10.1007/ s10640-018-0288-y

37. Roshan, E., Khabbazan, M. M., \& Held, H. (2019). Cost-risk trade-off of mitigation and solar geoengineering: Considering regional disparities under probabilistic climate sensitivity. Environal and Resource Economics, 72(1).

38. UNFCCC. (2011). Report of the Conference of the Parties on its seventeenth session, held in Durban from 28 November to 11 Addendum. Part Two: Action taken by the Conference of the Parties at its seventeenth session. Decision 1/CP.17: Establishment of an Ad Hoc Working Group on the Durban Platform for Enhanced Action FCCC/CP/2011/9/Add 1.

39. Lorenz, A., Schmidt, M. G. W., Kriegler, E., \& Held, H. (2012). Anticipating climate threshold damages. Environmental Modeling \& Assessment, 17(1), 163-175. https://doi.org/10.1007/ s10666-011-9282-2

40. Wigley, T. M. L., \& Raper, S. C. B. (2001). Interpretation of high projections for global-mean warming. Science, 293(5529), 451-454. https://doi.org/10.1126/science.1061604

41. Edenhofer, O., Bauer, N., \& Kriegler, E. (2005). The impact of technological change on climate protection and welfare: Insights from the model MIND. Ecological Economics, 54(2), 277-292. https://doi.org/10.1016/j.ecolecon.2004.12.030

42. Roe, G. H., \& Baker, M. B. (2007). Why is climate sensitivity so unpredictable? Science, 318(5850), 629-632. https://doi.org/ $10.1126 /$ science. 1144735

43. Schneider von Deimling, T., Held, H., Ganopolski, A., \& Rahmstorf, S. (2006). Climate sensitivity estimated from ensemble simulations of glacial climate. Climate Dynamics, 27(2), 149-163. https://doi. org/10.1007/s00382-006-0126-8

44. Howitt, R. (1995). Positive mathematical programming. American Journal of Agricultural Economics, 77(2), 329-342.

45. Neubersch, D. (2014). Value of information under climate targets: An application of cost-risk analysis. Hamburg, Germany: University of Hamburg.

46. Kriegler, E., \& Bruckner, T. (2004). Sensitivity analysis of emissions corridors for the 21 st century. Climatic Change, 66(3), 345-387. https://doi.org/10.1023/b:clim.0000044615. 75251.02

47. Klepper, G., \& Rickels, W. (2012). The real economics of climate engineering. Economics Research International, 2012, 20. https://doi.org/10.1155/2012/316564

48. Svoboda, T. (2017). The ethics of climate engineering: Solar radiation management and non-ideal justice. New York: Routledge.

49. Svoboda, T. K., Goes, M., \& Tuana, N. (2011). Sulfate aerosol geoengineering: The question of justice. Public Affairs Quarterly, $25,157-179$.

Publisher's Note Springer Nature remains neutral with regard to jurisdictional claims in published maps and institutional affiliations. 